\title{
Genotypic analysis of ticks species infesting cattle in Al-Diwaniyah abattoir
}

\author{
M.J. Ali ${ }^{1}{ }^{\circledR}$, W.R. Atiyah ${ }^{2}$, M.A. Al-Fatlawi ${ }^{1}{ }^{\circledR}$, and S.F. Klaif ${ }^{\circledR}$ \\ ${ }^{1}$ Department of Veterinary Microbiology, ${ }^{2}$ Department of Food Hygiene, ${ }^{3}$ Unit of Zoonotic Disease Research, College of \\ Veterinary Medicine, University of Al-Qadisiyah, Al-Diwaniyah, Iraq
}

Article information

Article history:

Received July 24, 2020

Accepted September 16, 2020

Available online October 1, 2021

Keywords:
H. detritum
H. excavatum
H. marginatum
Ticks
Al-Diwaniyah

Correspondence:

M.A. Al-Fatlawi

monyerr.abd@qu.edu.iq

\begin{abstract}
Different vectors are considered critical for disease transmission between animals; however, ticks play a significant role in the dissemination of various infectious illnesses of animals and human importance. The current work was carried out to categorize ticks genetically of those isolated from cattle that entered Al-Diwaniyah abattoir. In the present study, 50 tick samples were collected and subjected to microscopic examination and genetic-based methods of polymerase chain reaction and partial gene sequencing, both utilized the mitochondrial cytochrome c oxidase subunit I (COXI) gene as a genotyping element. The findings of the microscopic examination showed that the ticks were from Hyalomma spp. Further analysis, the polymerase chain reaction revealed the genus of Hyalomma of the ticks, but when the PGS was performed, one sample of $H$. detritum, three samples of $H$. excavatum, and two samples of $H$. marginatum were identified. When the phylogenetic analyses were conducted, $H$. detritum showed close genetic similarity to an isolate from Spain EU827695.1. H. excavatum revealed similarity with isolates from India MK863382.1 and Turkey MT230050.1. In contrast, H. marginatum displayed close identity to an isolate from Iran (MG557555.1). In conclusion, these findings may indicate evolutionary links of the locally identified isolates to different world isolates, probably due to the trade-moving of animals.
\end{abstract}

DOI: 10.33899/ijvs.2020.127772.1525, (A)Athors, 2021, College of Veterinary Medicine, University of Mosul.

This is an open access article under the CC BY 4.0 license (http://creativecommons.org/licenses/by/4.0/).

\section{Introduction}

Ticks are the most diversified arthropod vectors for human and livestock animals. Among such, ticks contain the most numerous collection of infectious agents. Human tick-borne pathogens, similar to the tick-borne associated diseases of farm animal species, are zoonotic diseases of livestock origin, in the epidemiology and ecology of tickborne disease, complex interactions between the biotic and abiotic. Studies have established the theory that zoonotic organisms and their vectors are present in various environments, and landscape epidemiology has resulted in communicable diseases. Alterations in ticks density, in prevalence, as well as in animal interactions, transport, land use, and habitat modifications, can affect tick and tickborne pathogenic demographic profiles (1-6).
There have been, are, and will continue to be modifications to the demographic makeup of tick communities. Changes of some of the known factors affecting tick populations will change the extent and abundance of these essential disease vectors. Synchronized changes are taking place among the complicated structures of micro- and macro-level factors requiring increased surveillance of these tick populations. In addition to many variables that may work together to create the observed changes, the geographical range and abundance of ticks are increasingly changing. A complex ecosystem of biotic and abiotic variables, including changes in animal and human demographics and behavior, influences both tick population densities and distributions. Aside from their immediate impact on ticks, a large number of tick-related micro-organisms and tick diseases, along with additional 
danger to public health of tick-like paralysis and other toxicity is affected by biotic and abiotic elements (7-10). The dynamic, evolving complexity of the tick vectors and tick-borne diseases and dissemination needs persistent surveillance, including studying tick vectors, pathogens, and epidemiological characteristics. The collaboration of multidisciplinary teams involved in tick detection, identification, intervention approaches, awareness, study and testing, scientific and organizational preparation as well as public engagement promote community health responses to vector-borne diseases. As ticks and transmitted diseases do not acknowledge foreign borders, every tick and tick-borne infection network should become part of any comprehensive foreign disease tracking program offering accurate, evidence-based coordination for health agencies, healthcare professionals, other decisionmakers, and stakeholders as well as the public $(11,12)$.

According to the information mentioned above, the current work was carried out to categorize ticks genetically of those isolated from cattle that entered Al-Diwaniyah abattoir. The study might place a start point for epidemiological surveillance of ticks and tick-borne diseases in Al-Diwaniyah City, the southern provinces, and, eventually, the whole country.

\section{Materials and methods}

\section{Samples and animals}

The study was performed between February and May, 2019. The current work involved taking 50 tick samples from cattle that were prepared to slaughtering. The ticks were collected using ether-soaked pieces of cotton with forceps. Then, ticks obtained from each animal were placed in a separate $70 \%$-ethanol-included container labeled with the animal sex, the collection date, and the part of the body from where the ticks were detached (13). After that, the ticks were transported to the Laboratory of Parasitology, Department of Microbiology, College of Veterinary Medicine, University of Al-Qadisiyah, Al-Diwaniyah City, Iraq.

\section{Microscopic examination}

The ticks were intensively examined under the evaluation of Prof. Dr. Monyer Abdulameir Abd Alfatlawi (specialist in veterinary parasitology), Head of Department of Microbiology, College of Veterinary Medicine, University of Al-Qadisiyah, Al-Diwaniyah City, Iraq. The ticks were visualized under a dissecting microscope and relying on standard information regarding methods and tick morphological features described by Soulsby (14) and Shubber et al. (15).

Genetic approaches

\section{Polymerase chain reaction}

Mitochondrial DNA was extracted using the gSYAN DNA Extraction Kit (Geneaid, USA) and following the kit protocol. For the initiation of the process, $200 \mathrm{mg}$ of each tick was used. A NanoDrop was utilized to evaluate the resulted DNA. The PCR was conducted using the primer set; F: AGGGTCCCCAGATATAGCATT and R: ACCGCCTGAAGGGTCAAAAA. The primer targeted a piece at $415 \mathrm{bp}$ of the COX1 gene (16). The AccuPower PCR PreMix Kit and relying on its instructions were employed for preparing the PCR reaction solution, which included using $5 \mu \mathrm{l}$ DNA, F and R primers $1.5 \mu 1 \quad 10$ pmol/each, and $12 \mu \mathrm{l} \mathrm{PCR}$ water. Then, the mixture was placed in the kit tubes that had a ready-mixture of essential components such as DNA polymerase, dNTPs, Tris-HCl $\mathrm{pH}$ : 9.0, $\mathrm{KCl}$, and $\mathrm{MgCl}_{2}$. Later, the mixture was briefly vortexed and entered the thermocycler (MJ-Mini BioRad, USA) at $94^{\circ} \mathrm{C}, 1 \mathrm{~min}, 1$ cycle of initial denaturation, 30 cycles of denaturation, annealing, and extension at $94^{\circ} \mathrm{C}$, $0.5 \mathrm{~min}, 58^{\circ} \mathrm{C}, 0.5 \mathrm{~min}$, and $72^{\circ} \mathrm{C}, 1 \mathrm{~min}$, respectively, and the final extension at $72^{\circ} \mathrm{C}, 5 \mathrm{~min}(16)$. After that, each well of a $1.5 \%$-agarose gel pre-mixed with $3 \mu$ l ethidium bromide was inserted with $10 \mu \mathrm{l}$ PCR product except one well that received $5 \mu 1100$ bp ladder. The gel was run on 100 volts and 80 Amp for $1 \mathrm{hr}$. Later, the gel and the bands were overviewed under a UV-light based visualizer.

\section{Partial gene sequencing}

The PGS was performed by the $\mathrm{AB}$ DNA sequencing system (Bioneer, Korea) using the purified PCR products of six samples and utilizing the same above primers. The sequencing data were deposited in the GeneBank database with an accession number for each isolate. These sequences were analyzed by recruiting the use of NCBI-based nucleotide websites and the MEGA 6.0 software for building the phylogenetic tree and identify comparable global isolates. The evolutionary distances were evaluated by the Maximum Composite Likelihood method.

\section{Results}

\section{Microscopic examination}

The findings of the ME showed that the ticks were from Hyalomma spp. The ME revealed characteristic morphological features of the mouth parts and genital pore (Figure 1A), Coxa (I, II, and III) (Figure 1B), and festoons (Figure $1 \mathrm{C}$ and D).

\section{Polymerase chain reaction}

Further analysis, the PCR revealed the genus of Hyalomma of the ticks. The amplification bands were at 415 bp (Figure 2).

\section{Partial gene sequencing and phylogenetic analyses}

The PGS uncovered that one sample of $H$. detritum, three samples of $H$. excavatum, and two samples of $H$. marginatum were identified. When the phylogenetic analyses were conducted, $H$. detritum showed close genetic similarity to an isolate from Spain EU827695.1 (Figure 
3A). H. excavatum revealed similarity with isolates from India MK863382.1 and Turkey MT230050.1 (Figure 3B). At the same time, $H$. marginatum displayed close identity to an isolate from Iran MG557555.1 (Figure 3C).

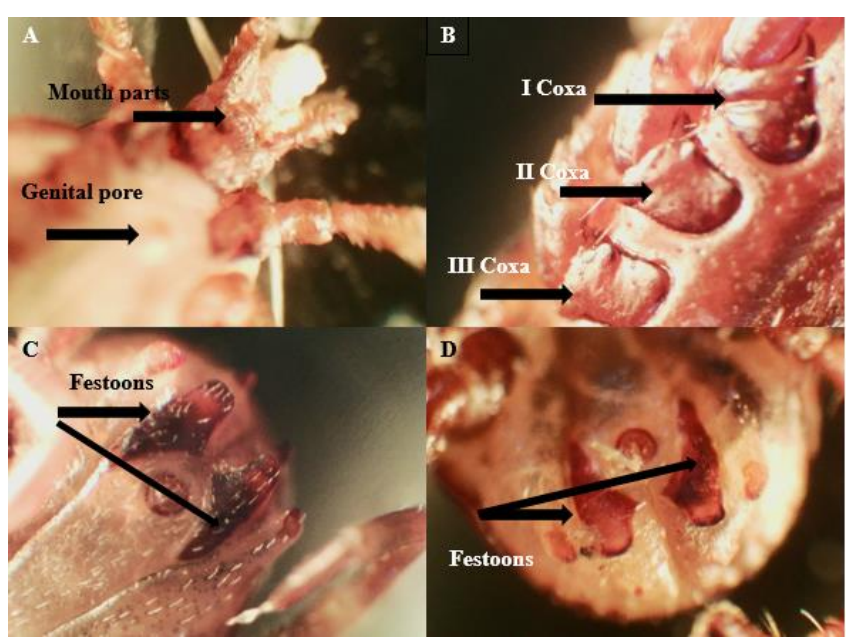

Figure 1: Microscopical examination of tick genus Hyalomma. A. Ventral surface: Mouth parts and genital pore. B. Ventral surface: I, II, and III Coxa. C\&D. Ventral surface: Festoons. Olympus (2.5X).

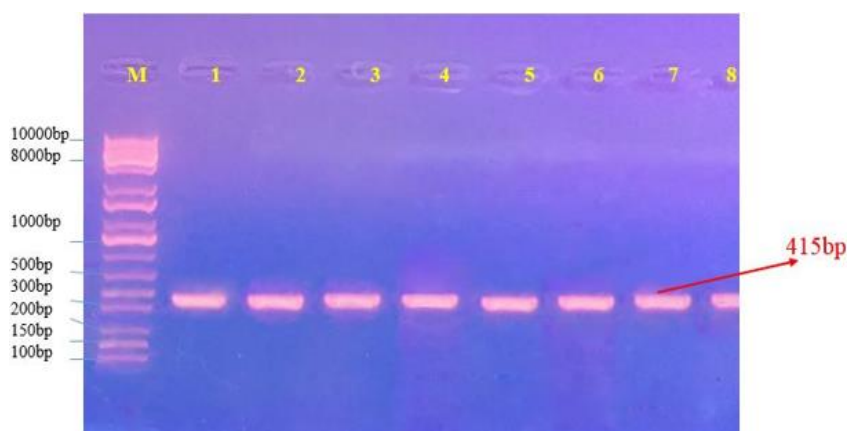

Figure 2: PCR analysis: Agarose gel electrophoresis 1\% shows the DNA fragments of the COX1 gene PCR products and the. Lane 1-8, 415bp Positive samples of genus Hyalomma, and M; a 10000 bp DNA ladder.

\section{Discussion}

Still, ticks and tick-borne-diseases represent a profound concern with a large global scale. These parasites exist with a broadly dense community of genera and species of human and animal involvement due to the direct effects of sucking blood from their victims and the infectious agents they transmit. For animals, infectious diseases from a long list can cause devastating effects on the health of wild and domestic animals such as protozoal illnesses; for example, babesiosis and theileriosis. On human health basis, many tick-borne diseases that represent a significant worrisome due to the consumption of beef and lamb, such as Crimean Congo hemorrhagic fever (CCHF) that showed up in Iraq on several occasions, the last one in $2018(17,18)$.

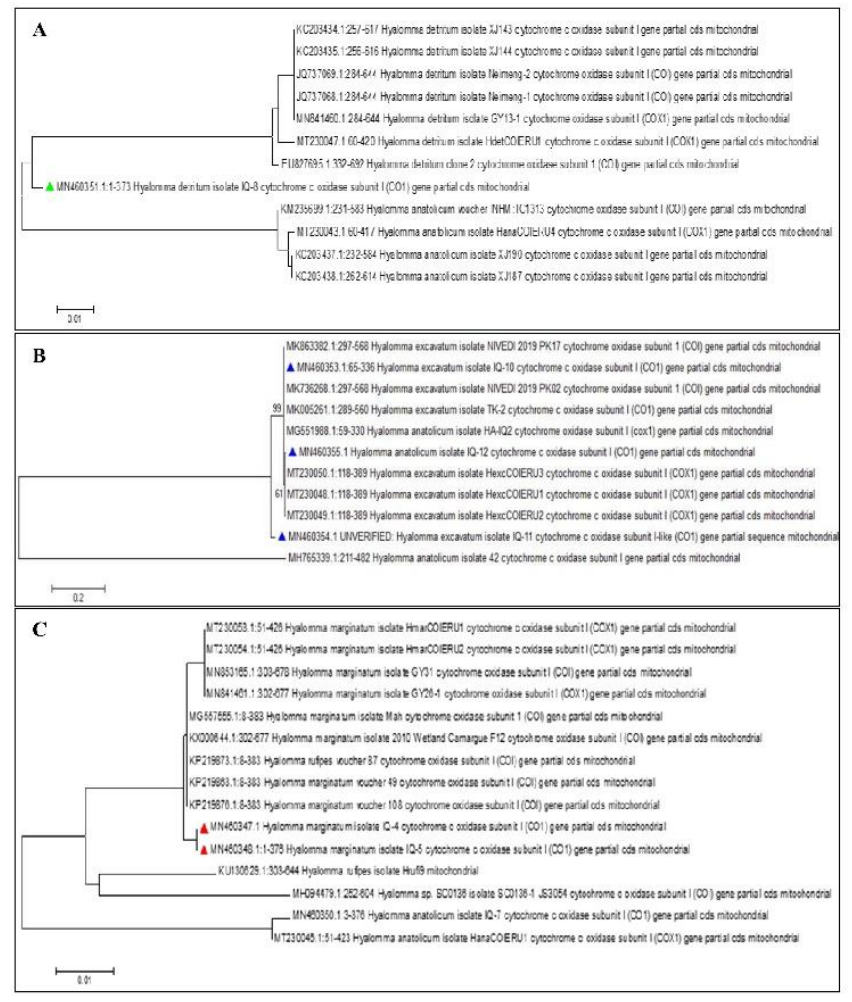

Figure 3: Phylogenetic tree based on the partial gene sequencing of COX1 gene from Hyalomma ticks. A. $H$. detritum: Genetically similar to an isolate from Spain EU827695.1. B. H. excavatum: Similarity to isolates from India MK863382.1 and Turkey MT230050.1. C. $H$. marginatum: Similar to an isolate from Iran MG557555.1.

Many ixodid ticks are used as both the CCHF vector and reservoir. Nevertheless, for the ecology of this virus, ticks of the Hyalomma genus are especially important. CCHF outbreaks are strongly related to the world-famous Hyalomma spp. The Hyalomma genus is a small, robust species of ticks that are well suited to survive in arid biotopes. In Morphology (well-formed rounded head, strong legs), physiology (successful low moisture metamorphosis), actions (active host search), a significant degree of tolerance to hot, and stable in open habitations is evident. The primary host of most species are different animal types, and consequently, these ticks are generally broadened. The majority of this genus species have three hosts, but there are also species of one-host and two-hosts. Early phases feed primarily on mammals and birds, but some species non-adult ticks infect Reptiles of individual species. Together, 27 Hyalomma species invade domestic and wildlife animals, but a few species such as $(H$. anatolicum, $H$. marginatum, $H$. nitidum) species are 
recognized as CCHF transmitters (19). The current results recorded the presence of $H$. marginatum, and according to the literature mentioned above, this species may assure the presence of the CCHF and probably its occurrence. Some of the Hyalomma species are considered rare, and if occurred, they go blood-feeding on cows/camels or cows, such as $H$. detritum and $H$. schulzei, respectively. Most Hyalomma species are active with high density during hot seasons rather than cold ones (20).

Several animal hosts, including pigs, camels, equines, horses, goats, and dogs, are accessible by $H$. excavatum, and it may target humans also. Based on the selection of hosts, it is served as a tick of two or three-host. The larvae and nymphs nourish on small vertebrates, birds, and humans with a low rate of presence in winters. This tick occurs in Egypt, Sudan, Eritrea, Iraq, Jordan, Italy, and Greece. CCHF is one of the major diseases that can be transmitted by $H$. excavatum. It can also transmit babesiosis, theileriosis, and rickettsiasis (21). The findings revealed evolutionary links of the locally identified isolates to different world isolates, probably due to the trademoving of food animals (22).

\section{Conclusion}

The tick species recognized in the current study are among those that can transmit dangerous diseases to animals and humans, such as babesiosis and Crimean Congo hemorrhagic. The species identified represent significant similarity with global strains and may indicate evolutionary links of the locally identified isolates to the global isolates, probably due to the trade-moving of food animals.

\section{Acknowledgment}

The authors thank College of Veterinary Medicine, University of Al-Qadisiyah.

\section{Conflict of interests}

No conflict.

\section{References}

1. Dantas-Torres F, Chomel BB, Otranto D. Ticks and tick-borne diseases: A One Health perspective. Trends Parasitol. 2012;28(10):437-46. DOI: 10.1016/j.pt.2012.07.003

2. Dantas TF. Climate change, biodiversity, ticks and tick-borne diseases: The butterfly effect. Int $\mathrm{J}$ Parasitol Parasites Wild. 2015;4(3):452-61. DOI: 10.1016/j.ijppaw.2015.07.001

3. Baneth G. Tick-borne infections of animals and humans: A common ground. Int J Parasitol. 2014;44(9):591-6. DOI: 10.1016/j.ijpara.2014.03.011

4. Pfaffle M, Littwin N, Muders SV, Petney TN. The ecology of tickborne diseases. Int J Parasitol. 2013;43(12-13):1059-77. DOI: 10.1016/j.ijpara.2013.06.009
5. Colwell DD, Dantas TF, Otranto D. Vector-borne parasitic zoonoses: Emerging scenarios and new perspectives. Vet Parasitol. 2011;182(1):14-21. DOI: 10.1016/j.vetpar.2011.07.012

6. Jongejan F, Uilenberg G. The global importance of ticks. Parasitology. 2004;129:3-14. DOI: 10.1017/S0031182004005967

7. Sonenshine DE. Range expansion of tick disease vectors in north America: Implications for spread of tick-borne disease. Int J Environ Res Public Health. 2018;15(3):478. DOI: 10.3390/ijerph15030478

8. Mans BJ, Gothe R, Neitz AWH. Biochemical perspectives on paralysis and other forms of toxicoses caused by ticks. Parasitol. 2004;129:95-111. DOI: $10.1017 /$ S0031182003004670

9. Edlow JA, McGillicuddy DC. Tick Paralysis. Infect Dis Clin North Am. 2008;22(3):397-413.DOI: 10.1016/j.idc.2008.03.005

10. Eisen RJ, Kugeler KJ, Eisen L, Beard CB, Paddock CD. Tick-borne zoonoses in the United States: Persistent and emerging threats to human health. ILAR J. 2017;58(3):319-35. DOI: 10.1093/ilar/ilx005

11. Thompson PN, Etter E. Epidemiological surveillance methods for vector-borne diseases. OIE Rev Sci Tech. 2015;34(1):235-47. DOI: 10.20506/rst.34.1.2356

12. Braks M, Medlock JM, Hubalek Z, Hjertqvist M, Perrin Y, Lancelot R, Ducheyne E, Hendrickx G, Stroo A, Heyman P, Sprong H. Vectorborne disease intelligence: Strategies to deal with disease burden and threats. Front Public Heal. 2014;2:280. DOI: 10.3389/fpubh.2014.00280

13. Alfatlawi MA, Jasim AA, Jarad NE, Khlaif SF. Clinical and molecular identification of ruling Theileria annulata strains in cattle calves in Al-Diwaniyah province, Iraq. Iraqi J Vet Sci. 2021;35(1):115-119. DOI: 10.33899/ijvs.2020.126429.1319

14. Alfatlawi MA, Ismail YK, Ali MJ, Karawan AC, Ibadi IN. Molecular differentiation of Thysaniezia (Helictometra) giardi and Moniezia species based on 18s rRNA gene in small ruminants. Iraqi J Vet Sci. 2021;35(1):105-108. DOI: $10.33899 /$ ijvs.2020.126407.1313

15. Ali MJ, Karawan AC, Al-Fetly DR, Alfatlawi MA. Synergizing the deltamethrin larvicidal activity against Aedes albopictus larvae using cinnamaldehyde in Diwaniyah, Iraq. Iraqi J Vet Sci. 2020;34(2):317320. DOI: 10.33899/ijvs.2019.126026.1212

16. Al-Fatlawi MAA, Alkhaled MJA, Albayati HH. Morphological and phylogenetic study of Hyalomma anatolicum in Al-Najaf, Iraq. Iraqi J Vet Sci. 2018;32(2):261-266. DOI: 10.33899/ijvs.2019.153860

17. Boushab BM, Kelly M, Kebe H, Bollahi MA, Basco LK. Crimean Congo Hemorrhagic Fever, Mauritania. Emerg Infec Dis. 2020;26(4):817-818. DOI: 10.3201/eid2604.191292

18. Blair PW, Kuhn JH, Pecor DB, Apanaskevich DA, Kortepeter MG, Cardile AP, Ramos AP, Keshtkar JM. An emerging biothreat: Crimean-Congo hemorrhagic fever virus in southern and western Asia. Am J Trop Med Hyg. 2019;100(1):16-23. DOI: 10.4269/ajtmh.18-0553

19. Khan V, Zala DB, Joshi KM. Occurrence of Hyalomma, (Acari: Ixodidae) Koch, 1844 on domestic animal in the Union Territory of Dadra and Nagar Haveli, Indian. J Parasit Dis. 2016;40(2):543-5. DOI: 10.1007/s12639-014-0490-y

20. Choubdar N, Oshaghi MA, Rafinejad J, Pourmand MR, MalekiRavasan N, Salehi-Vaziri M, Telmadarraiy Z, Karimian F, Koosha M, Rahimi-Foroushani A, Masoomi S, Arzamani K, Nejati J, Karami M, Mozaffari E, Salim-Abadi Y, Asl EM, Taghilou B, Shirani M. Effect of meteorological factors on hyalomma species composition and their host preference, seasonal prevalence and infection status to CrimeanCongo Haemorrhagic Fever in Iran. J Arthropod Borne Dis. 2019;13(3):268-83. DOI: 10.18502/jad.v13i3.1537

21. Abdullah HM, El-Shanawany EE, Abdel-Shafy S, Abou-Zeina HAA, Abdel-Rahman EH. Molecular and immunological characterization of Hyalomma dromedarii and Hyalomma excavatum (Acari: Ixodidae) vectors of Q fever in camels. Vet World. 2018;11(8):1109-19. DOI: 10.14202/vetworld.2018.1109-1119

22. A-Fatlawy HH, Alfatlawi MA. Morphological and molecular identification of Parabronema skrjabini of camels (Camelus dromedary) in Najaf province. Iraqi J Vet Sci. 2021;35(3):507-512. DOI: $\underline{10.33899 / \text { ijvs.2020.127101.1459 }}$ 


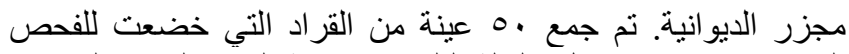

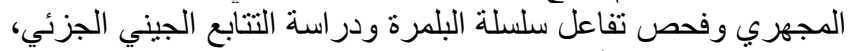

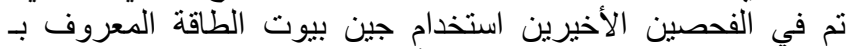

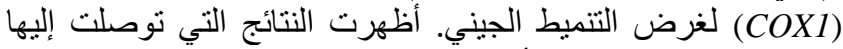

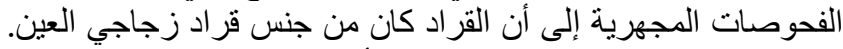

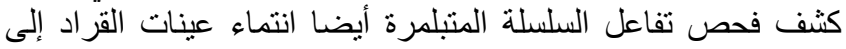

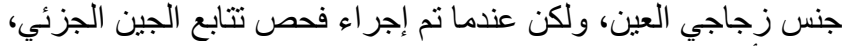

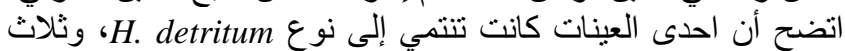

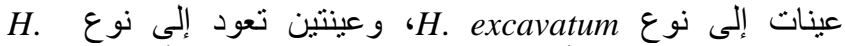
marginatum

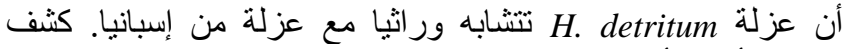

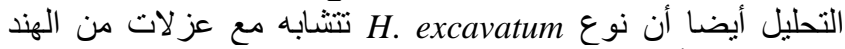

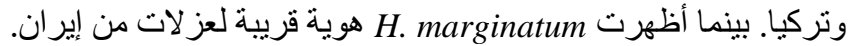

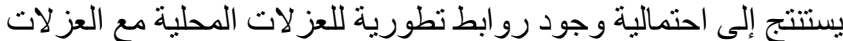

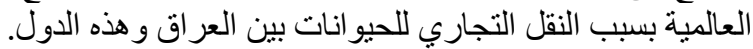

\section{التحليل الجيني لأنواع القراد المتطقلة عل الماشية المذبوحة في مجزرة الديوانية الاعية}

منصور جدعان علي'، وسام رحيم عطيهץ، منير عبد الأمير عبد الفتلاوي ا و صبا فلاح كليف

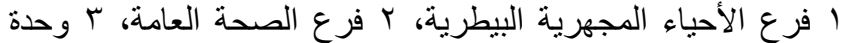
بحوث الأمراض الاحياء الشتركة، كلية الطب البيطري، جامعة القادسية،

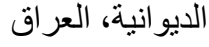

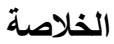

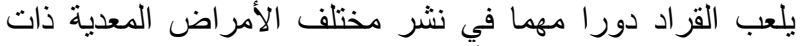

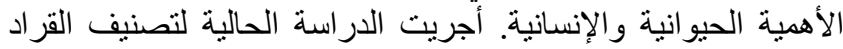

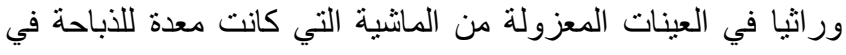

